\title{
Review Article \\ Recent Development of Trifluoromethyl Reagents: A Review
}

\author{
A. C. Bhowmick* \\ Department of Chemistry, Mawlana Bhashani Science and Technology University, Santosh, \\ Tangail-1902, Bangladesh
}

Received 9 September 2020, accepted in final revised form 11 October 2020

\begin{abstract}
Organic molecules having fluorine atom are very important since it increases the lipophilicity that is essential for drug development and additionally strong carbon-fluorine (C-F) bond makes the material unique, especially for material chemistry. Instead of elemental fluorine, recently trifluoromethylated materials $\left(\mathrm{CF}_{3}\right)$ have drawn considerable attention in the agrochemical and pharmaceutical industries. In the continuous development of the trifluoromethylated reagents, over the last few decades, some trifluoromethylated reagents have been well developed and the efficiency of these reagents for incorporating $\mathrm{CF}_{3}$ group on different types of substrates are also studied. In this article, all types of available trifluoromethylated reagents and their effectiveness on suitable substrates are summarized. Additionally, the methods of synthesizing trifluoromethylated substrates are discussed. Finally, the scopes of the development of new reagents after focusing on the shortcomings of the current reagents are also discussed.
\end{abstract}

Keywords: Nucleophilic; Electrophilic; Free radical; Solvent; Electrochemical.

(c) 2021 JSR Publications. ISSN: 2070-0237 (Print); 2070-0245 (Online). All rights reserved. doi: http://dx.doi.org/10.3329/jsr.v13i1.48992

J. Sci. Res. 13 (1), 317-333 (2021)

\section{Contents}

1. Introduction

2. Aim of the review

3. Different types of methods

3.1. Silver salt catalysis

3.1.1. Light mediated trifluoromethylation using Ag-salts

3.1.2. Silver catalyzed 1,4-naphthoquinone derivatives

3.2. Copper catalysis

3.2.1. Hydrotrifluoromethylation of alkene

3.2.2. Trifluoromethylation of aromatic and heteroaromatic systems

3.3. Togni reagents

3.3.1. Synthesis of Togni reagents 2

3.3.2. Synthesis of Togni reagents 1

3.4. Decarbonylative

\footnotetext{
*Corresponding author: bhowmick_mbstu@yahoo.com
} 
3.4.1. Deoxyfluorination of aromatic acids

3.4.2. Deoxyfluorination of aliphatic acids

3.5. Ruppert Prakash reagents

3.5.1. Trifluoromethylation of aryliodide

3.6. Langlois reagent

3.6.1. Sodium trifluoromethanesulfinate as $\mathrm{CF}_{3}$ source

3.7. Metal complexes in catalysis

3.7.1. Pd catalyzed reaction

3.7.2. Ni catalyzed reaction

3.8. Electrochemical

3.8.1. Electrosynthesis of arenes and heteroarenes

3.9. Light-driven

3.10.Umemoto reagents

3.10.1. Types of Umemoto reagents

3.11. Future direction

4. Conclusion

\section{Introduction}

Incorporation of trifluoromethyl $\left(\mathrm{CF}_{3}\right)$ group on different types of organic molecules is a very important aspect, as these substrates are used in the development of pharmaceuticals [1-4] and agro-products [5-7]. These fluorinated materials help the stability of drugs [8] and lipophilicity $[9,10]$. So, it is important to have a diverse number of trifluoromethyl containing target molecules [11-14] and in this way, researchers are trying to continuously develop cheap and easily fabricable trifluoromethyl reagents (Scheme 1). Already some efficient methods are being used to synthesize trifluoromethyl containing substrates such as Ruppert-Prakash $\left(\mathrm{TMSCF}_{3}\right)$ [15], Togni reagent [16], Umemoto reagents [17], and Langlois reagent $\left(\mathrm{CF}_{3} \mathrm{SO}_{2} \mathrm{Na}\right)$ [18]. In these methods, trifluoromethyl either acts as electrophile [19], nucleophile [20] or as free radical [21-23].

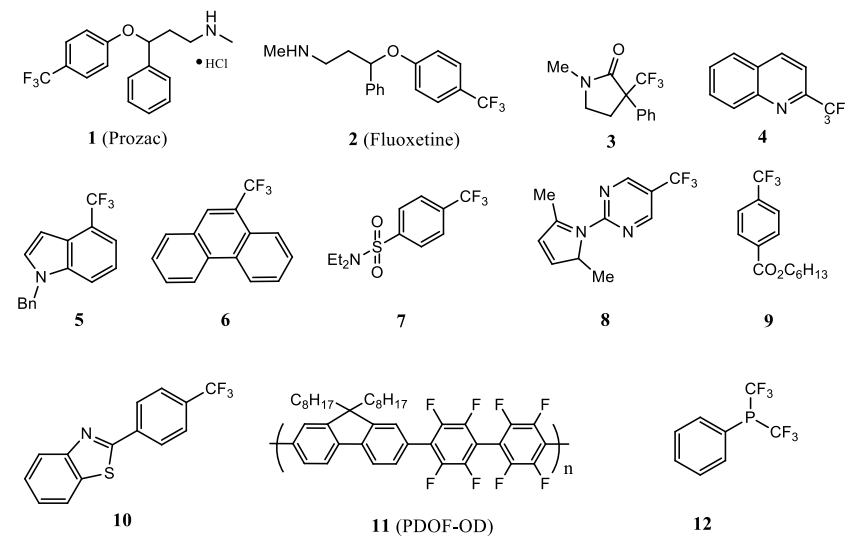

Scheme 1. Examples of fluorinated compounds [1,3,9,11,32,52,73] and a fluorinated polymer [27]. 
It is worth mentioning that incorporating trifluoromethyl $\left(\mathrm{CF}_{3}\right)$ on organic molecules changes their properties and, in this way, fluorinated substrates are very important for the material's chemistry [24-26] for designing some smart materials such as semiconductor in organic light-emitting diode (OLED) [27] and organic field-effect transistor (OFET) [28]. It is also well known that handling fluorinated materials need extra precaution since they produce toxic chemicals [29] during chemical reaction with substrates. That is why there is still a big challenge working with fluorinated reagents [30]. Further, current trifluoromethylating reagents have some limitations such as toxicity, moisture sensitivity, and explosiveness [31]. Considering the following facts, researchers are trying to develop a facile method of synthesizing trifluoromethylated reagents and measuring their effectiveness for preparing trifluoromethylated substrates.

\section{Aim of the Review}

There is a wide variety of review articles for explaining the trifluoromethyl $\left(\mathrm{CF}_{3}\right)$ reagents for developing trifluromethylated organic molecules. A few of them are concentrated on specific areas such as Umemoto's reagent [21], reactions in aqueous media [31], hypervalent iodine reagents [32], $\mathrm{CF}_{3}-\mathrm{S}$ transfer agents [33] and photolytic reactions [34]. Further, a few reviews have been discussed fluorine effect on chemical reactions [35] and in some reviews, it is described some selective trifluoromethylated reactions [36-39]. Although, a good number of review articles are available, sometimes it is difficult to extract important ideas from the vast amount of discussion. Besides, it is not known any review article that summarized all available trifluoromethylated reagents with highlighting the specific type of substrates scopes where most of them concentrated on one specific reagent and its substrate scopes. That is why a short review incorporating all types of available reagents is very essential especially for young researchers for getting incite and developing new trifluoromrthylated organic substrates. Considering this, here, the review has been concentrated on all types of the current development of trifluoromethyl $\left(\mathrm{CF}_{3}\right)$ reagents up to 2020 and depending on these reagents probable target products are being discussed. So, it is believed that the reader will find a summary of all efficient reagents with their suitability on different organic targets and further, this will help researchers to identify easily suitable reagents/methods during the synthesis of trifluoromethylated materials. Also, it is well known that although a lot of methods are available all methods are not good for organic synthesis due to their low yield. Hence, some selective methods are described in this review that will be helpful to identify effective methods to prepare a gram scale of substrates during organic synthesis since reaction yields are discussed along with substrate scopes. It will also be beneficial having incite of the area needs to develop further after reading this review (section 3.11.). The review discusses very briefly all types of trifluoromethylated reagents, which is a benefit of this review to readers. 


\section{Different Types of Methods}

\subsection{Silver salt catalysis}

\subsubsection{Light mediated trifluoromethylation using Ag-salts}

It was used anatase $\mathrm{TiO}_{2}$ powder, arene, silver trifluoroacetate, trifluoroacetic acid, and the solvent was used dry acetonitrile. The reaction was stirred under an inert condition with a $500 \mathrm{~W} \mathrm{Hg}$ lamp for $24 \mathrm{~h}$. This method easily helped to incorporate the trifluoromethyl $\left(\mathrm{CF}_{3}\right)$ group on aromatic systems. Even substituted aromatic systems (Ar$\mathrm{R}, \mathrm{R}=\mathrm{H}, \mathrm{X}, \mathrm{CH}_{3}, \mathrm{CO}_{2} \mathrm{R}, \mathrm{CH}_{2} \mathrm{NO}_{2}$, etc.) worked very smoothly. The demerit of the method is that reaction yields were mentioned moderate $10-50 \%$ [40].

\subsubsection{Silver catalyzed 1,4-naphthoquinone derivatives}

In this method, trifluoromethyl $\left(\mathrm{CF}_{3}\right)$ substituted 26 different types of 1,4-naphthoquinone derivatives, which were prepared with $51-81 \%$ yield since the compounds may have therapeutic activity. The synthetic procedure involved a dry Schlenk line tube substituted 1,4-Naphthaquinone, Togni reagent, silver acetate, DPPF (1,1'-bis (diphenylphosphino)ferrocene), alkene (in 1,2-dichloroethane). Under the inert condition, the reaction was stirred at $75{ }^{\circ} \mathrm{C}$ for $12 \mathrm{~h}$. The unique significance of the method is that by changing the alkene and 1,4-naphthoquinone moiety, one can easily synthesize the expected trifluoromethyl $\left(\mathrm{CF}_{3}\right)$ substituted molecules [41] (Scheme 2.).

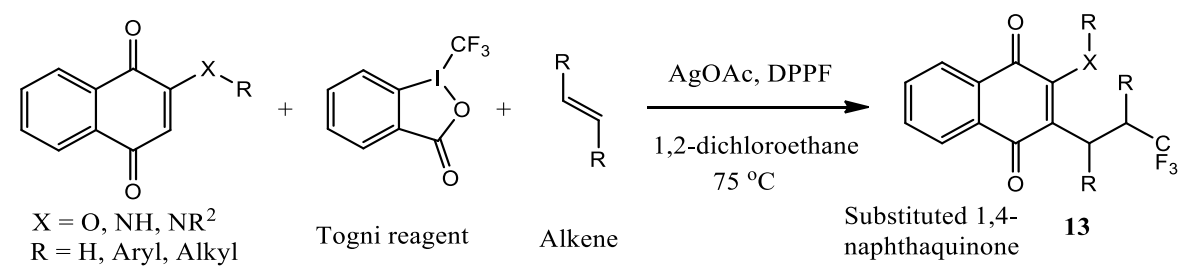

Scheme 2. Synthesis of substituted 1,4-naphthoquinone.

\subsection{Copper catalysis}

\subsubsection{Hydrotrifluoromethylation of alkene}

To a dry Schlenk line tube, silane and $t$-BuONa was added. The reaction was stirred at $100{ }^{\circ} \mathrm{C}$ for $1 \mathrm{~h}$ in dry DMF. Later $(\mathrm{Py}) \mathrm{Cu}\left(\mathrm{CF}_{3}\right)_{3}$ and alkyne were added and again it was stirred for $12 \mathrm{~h}$. In this way, trifluoromethylation happens by $\mathrm{Cu}$ catalyst [42] (Scheme 3).

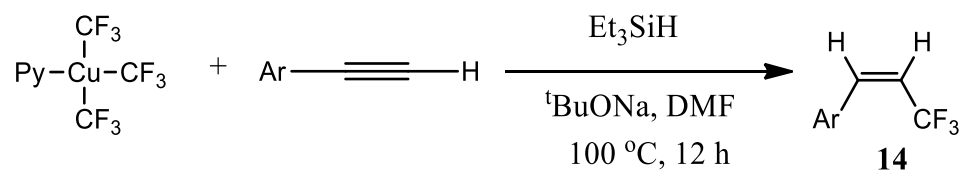

Scheme 3. Trifluoromethylation of arylalkyne by the copper catalyst. 
Synthesis of $(\mathrm{Py}) \mathrm{Cu}\left(\mathrm{CF}_{3}\right)_{3}$ catalyst: It was stirred a mixture of $\mathrm{CuI}, \mathrm{AgF}$, pyridine, and $\mathrm{TMSCF}_{3}$ in dry DMF for $21 \mathrm{~h}$ at room temperature under the inert condition to get the final catalyst $(\mathrm{Py}) \mathrm{Cu}\left(\mathrm{CF}_{3}\right)_{3}$ [43].

Szabo et al. [44] used $\left(\mathrm{PPh}_{3}\right)_{3} \mathrm{CuCF}_{3}$ [45] to prepare allylic trifluoromethylated compounds. Grushin et al. [46] used $\mathrm{CuCF}_{3}$ to introduce trifluoromethyl $\left(\mathrm{CF}_{3}\right)$ on aromatic diazonium salts. Li et al. $[47,48]$ did trifluoromethylation of an alkyl halide with a yield of up to $98 \%$ (Scheme 4).

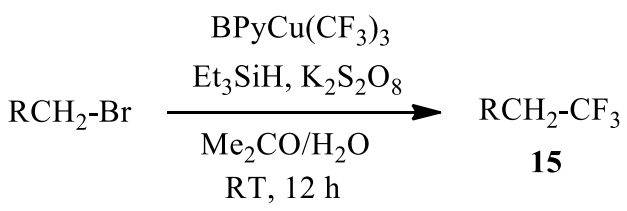

Scheme 4. Trifluoromethylation of alkyl halide.

Hartwig et al. used (Phen) $\mathrm{CuR}_{\mathrm{f}}\left(\mathrm{R}_{\mathrm{f}}=\mathrm{CF}_{3}, \mathrm{CF}_{2} \mathrm{CF}_{3}\right.$ etc.) for introducing trifluoromethyl $\left(\mathrm{CF}_{3}\right)$ on heteroarylbromide [49] and aryliodides [50]. Vicic et al. [51] used $\mathrm{LCu}(\mathrm{I})-\mathrm{CF}_{3}$ for preparing different types of organic halides under the mild condition with a $99 \%$ yield.

\subsubsection{Trifluoromethylation of aromatic and heteroaromatic systems}

A successful method of incorporating trifluoromethyl was developed by Buchwald et al. [52] where it was used flow method. Shortly, CuI, pyridine, $\mathrm{CF}_{3} \mathrm{COOK}, \mathrm{N}$ methylpyrrolidone (NMP), and 4-iodobiphenyl were injected in a preheated $\left(200{ }^{\circ} \mathrm{C}\right)$ stainless steel tube reactor for $16 \mathrm{~min}$. After isolating the target compound the yield was found $87 \%$ (Scheme 5). It was mentioned that ester-, nitro-, amide-, sulfonamide- and chloro-substituted compounds gave good yield and were tolerated under flow temperature. The method was found also efficient for a variety of heterocyclic compounds such as indole, pyridines, pyrazine, pyrimidine, isoquinoline, quinoline, pyrrolopyridine, and imidazopyridine. Using this method two grams of trifluoromethylated product were isolated from 4-iodobenzoate.

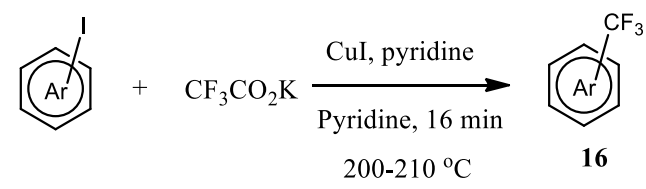

Scheme 5. Trifluoromethylation of aromatic systems.

\subsection{Togni reagent}

\subsubsection{Synthesis of Togni reagents 2}

A beaker was cooled in ice-salt mixtures with a magnetic stir bar at $0{ }^{\circ} \mathrm{C}$. Next, it was added $\mathrm{H}_{2} \mathrm{SO}_{4}$ in the beaker. In this cooled acid, it was added methyl anthranilate (17) and 
sodium nitrite that was dissolved in water. This mixture was heated $\left(40{ }^{\circ} \mathrm{C}\right)$ and added sequentially potassium iodide, $\mathrm{H}_{2} \mathrm{SO}_{4}$, sodium hydrosulfite. Finally, methyl-2iodobenzoate (18) is collected and purified (Scheme 3.5). This reaction mixture was added to dry ether with methylmagnesium iodide and the reaction was stirred at $-30{ }^{\circ} \mathrm{C}$ for $6 \mathrm{~h}$ and 2-(2-iodophenyl)propan-2-ol (19) is formed and purified. This material was heated at $75{ }^{\circ} \mathrm{C}$ in dry acetonitrile and trichloroisocyanuric acid and 1-Chloro-3,3-dimethyl-1,2benziodoxole (20) formed and purified. The chloro product was stirred with dry potassium fluoride in dry acetonitrile and added $\mathrm{TMSCF}_{3}$ with stirring at $-30{ }^{\circ} \mathrm{C}$ for $6 \mathrm{~h}$. Later, it was stirred at $-10{ }^{\circ} \mathrm{C}$ for $12 \mathrm{~h}$ leads to Togni reagent 2 (21) with 85-91\% yield [14] (Scheme $6)$.<smiles>COC(=O)c1ccccc1N</smiles>

17<smiles>COC(=O)c1cccc(C=O)c1I</smiles><smiles>CC1(C)OI(C(F)(F)F)c2ccccc21</smiles>

Togni reagent 2 21

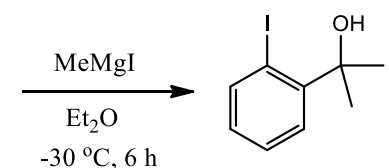

$-30^{\circ} \mathrm{C}, 6 \mathrm{~h}$ 2-(2-iodophenyl) propan-2-ol (19)

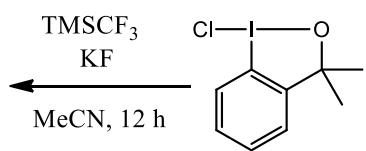

$-10{ }^{\circ} \mathrm{C}$ 20

Scheme 6. Synthesis of Togni reagent 2.

\subsubsection{Synthesis of Togni reagents 1}

One-pot synthesis of Togni reagent 1 was done from the reaction of 2-iodobenzoic acid, $\mathrm{KOAc}$, and trichloroisocyanuric acid heating at $75{ }^{\circ} \mathrm{C}$ for $2 \mathrm{~h}$ in dry acetonitrile. Later, this was stirred with $\mathrm{TMSCF}_{3}$ and gave Togni reagent 1 with a $75 \%$ yield [14] (Scheme 7).

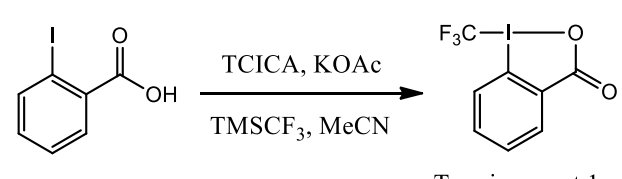

Scheme 7. One-pot synthesis of Togni reagent.

Using Togni reagents 1 and 2, different research groups prepared a large family of trifluoromethylated substrates. Togni group [53] prepared primary, secondary aryl- and alkylphosphines and lactams [9], Vincent et al. [54] prepared different types of alkenes, Shen group [55] used various types of boronic acids, Yu et al. [56] prepared trifluoromethylated dihydroisoquinolinones/indolines, $\mathrm{He}$ et al. [57] prepared 
$O$-homoallyl benzimidates, and Gong et al. [58] introduced trifluoromethyl group on different types of alkyl iodides.

\subsection{Decarbonylative reaction}

\subsubsection{Deoxyfluorination of aromatic acids}

One of the efficient methods was using sulfur tetrafluoride, which was first introduced by Engelhardt group [59,60]. An acid (starting material) was placed in $500 \mathrm{~mL}$ autoclave, it was cooled by liquid nitrogen and anhydrous hydrofluoric acid (HF) was added. Next, $\mathrm{SF}_{4}$ was added to the vessel and the mixture was gradually warmed to room temperature and heated at $85{ }^{\circ} \mathrm{C}$ for $24 \mathrm{~h}$. Here, deoxyfluorination happened on heteroaromatic (substituted) and cinnamic acid into trifluoromethylated compounds (52-93\%) [61] (Scheme 8). Trifluoromethylation also went well in heterocyclic acids (45-91\%) having five-membered (45-88\%) and six-membered rings (54-89\%), quinolines (89\%), isoquinolines $(84 \%)$, pyrazole $(87 \%)$, aniline (55-84\%), piperidines $(66-82 \%)$ and amino acids (73-91\%). The good thing is that this method helps to prepare those substrates in gram scale.

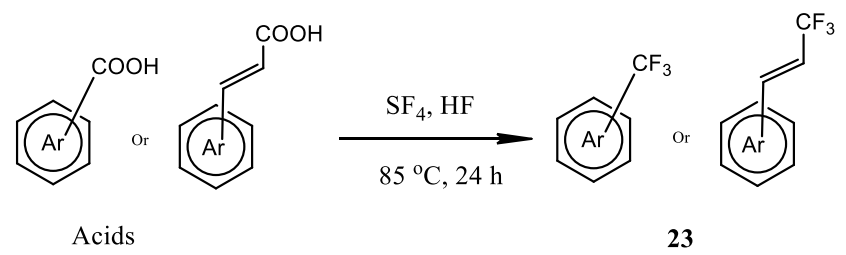

Scheme 8. Deoxyfluorinative trifluoromethylation of heteroaromatic and cinnamic acids.

\subsubsection{Deoxyfluorination of aliphatic acids}

Different types of aliphatic trifluoromethyl derivatives have been prepared from aliphatic acids almost as same as shown in section 3.4.1 (Scheme 9) [62]. The reactions went smoothly in gram scale for different types of primary, secondary, tertiary, and $\alpha$-halogeno acids, cyclic amines, and $\alpha$-amino acids with retaining stereo and absolute configuration of chiral centers. The method is developed by Engelhardt [60], Li [48], and MacMillan [63], however, the following method is better since it does not need liquid hydrofluoric acid (HF) and, also, chiral centers remain unaltered.

$$
\begin{aligned}
& \mathrm{R}-\mathrm{CO}_{2} \mathrm{H} \underset{\mathrm{SF}_{4}, \mathrm{H}_{2} \mathrm{O}}{55^{\circ} \mathrm{C}} \rightarrow \underset{\mathbf{2 4}}{\mathrm{R}-\mathrm{CF}_{3}} \\
& \left(\mathrm{R}=1^{\circ}, 2^{\circ}, 3^{\circ} \text { alkyl etc. }\right)
\end{aligned}
$$

Scheme 9. Deoxyfluorination of aliphatic carboxylic acid. 


\subsection{Ruppert-Prakash reagents}

\subsubsection{Trifluoromethylation of aryliodide}

In a reaction vial, $\mathrm{CuI}, t$-BuONa, and NMP ( $N$-methylpyrolidone) were stirred at room temperature for $10 \mathrm{~min}$. Later, $N, N^{\prime}$-dimethylenendiamine was added to the above reaction mixture. After $2 \mathrm{~min} \mathrm{AgF}$ and $\mathrm{Me}_{3} \mathrm{SiCF}_{3}$ were added to the reaction mixture. Fitted with a teflon screw cap, the reaction heated at $90{ }^{\circ} \mathrm{C}$ for $30 \mathrm{~min}$. After cooling, a few more portions of $\mathrm{Me}_{3} \mathrm{SiCF}_{3}$ were added and, finally, the reaction was stirred for $5 \mathrm{~h}$ at $90{ }^{\circ} \mathrm{C}$ (Scheme 10). In this method, different types of iodoarenes were used and yields were noted $47-98 \%$. It is said that $\mathrm{Cu}$ and $\mathrm{Ag}$ both played a role in this type of transformation.

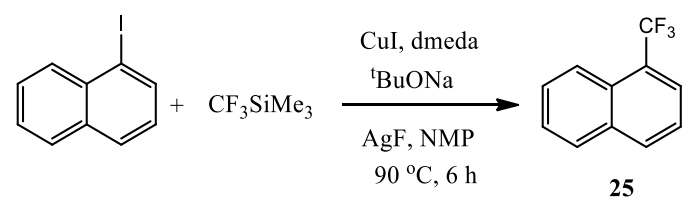

Scheme 10. Trifluoromethylation of iodoarene.

Similarly, using the reagent $\mathrm{Me}_{3} \mathrm{SiCF}_{3}$, some other types of organic compounds such as isoindolinones, isoquinolinones, 2-pyridinones, and other heterocycles were prepared [64]. Browne's group [65] also transformed $\mathrm{C}-\mathrm{N}$ to $\mathrm{C}-\mathrm{CF}_{3}$ through Sandmeyer reaction using this reagent $\left(\mathrm{Me}_{3} \mathrm{SiCF}_{3}\right)$.

\subsection{Langlois reagent}

\subsubsection{Sodium trifluoromethanesulfinate as $\mathrm{CF}_{3}$ source}

In this method, sodium trifluoromethanesulfinate is used and tert-butyl hydroperoxide is used as a source of oxidizer. A catalytic amount of $\mathrm{Cu}\left(\mathrm{OSO}_{2} \mathrm{CF}_{3}\right)_{2}$ was used and the reaction was done in acetonitrile at $20{ }^{\circ} \mathrm{C}$. This reagent helps to introduce $\mathrm{CF}_{3}$ on a wide variety of substituted aromatic systems (Scheme 11) with the highest yield up to $90 \%$ [18].

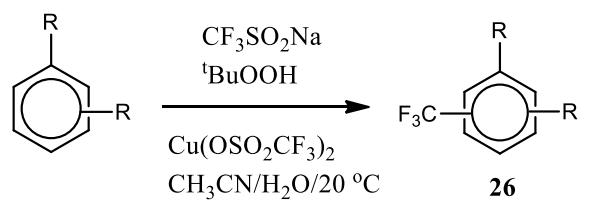

Scheme 11. Trifluoromethylation of aromatic compounds by using Langlois reagent.

A big advantage of this reagent is that it is very cheap compare to other available reagents and triflinate salt is air stable. Triflinate salt is also easy to prepare by using bromotrifluoromethane and sodiumdithionite or zinc/ $\mathrm{SO}_{2}$. Later, different research groups 
prepared different types of trifluoromethylated compounds by using this reagent. Wang's group [66] prepared different types of trifluoromethylated oxindoles from activated alkenes with a $94 \%$ yield where he used $\mathrm{K}_{2} \mathrm{~S}_{2} \mathrm{O}_{8}$ as oxidant (Scheme 12).

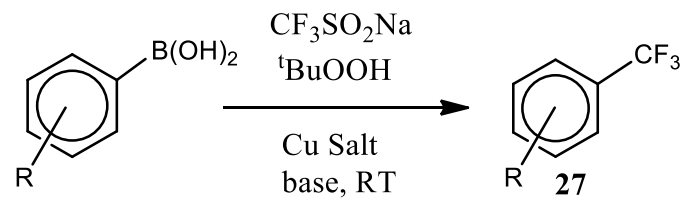

Scheme 12. Langlois reagent for trifluoromethylation of arylboronic acids.

Like Wang's group, Lipshutz et al. [67] prepared different types of oxindoles by using Langlois reagent, $\mathrm{Cu}$ salt, tetrametylethylenediamine (TMEDA), and tert-butyl hydroperoxide (TBHP) in water with a yield up to $87 \%$ (Scheme 13).

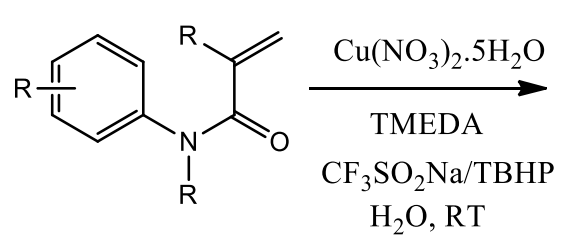

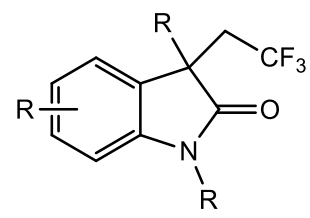

28

Scheme 13. Copper-catalyzed trifluoromethylation of oxindoles by using Langlois reagent.

Sanford group [68] used $t$-BuOOH, Langlois reagent, and different types of arylboronic acids. It is also noted that aryl boronic acids having electron-donating groups such as alkyl, alkoxy, and phenoxy, and the presence of $\mathrm{NaHCO}_{3}$ and $(\mathrm{MeCN})_{4} \mathrm{CuPF}_{6}$ lead to excellent yield. Liu's group [69] studied alkene in dimethyl sulfoxide (DMSO) and found a good yield of up to $95 \%$ (Scheme 14).

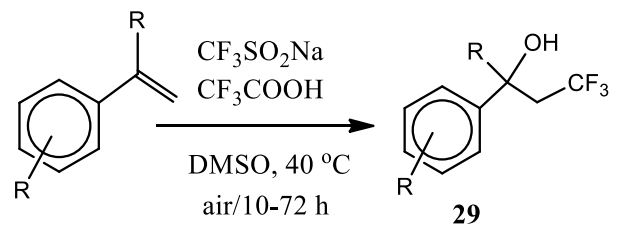

Scheme 14. Hydroxytrifluormethylation of an alkene by Langlois reagent.

\subsection{Metal complexes in catalysis}

\subsubsection{Pd catalyzed reaction}

Different types of palladium complexes were used for the preparation of trifluoromethylated compounds. These types of metal complexes are only suitable to get $\mathrm{Ar}-\mathrm{CF}_{3}$ complexes. For example, Sanford et al. [70] used $(\mathrm{L})_{2} \mathrm{Pd}^{\mathrm{II}}(\mathrm{Ar})\left(\mathrm{CF}_{3}\right)$ and (dtbpy) $\mathrm{Pd}^{\mathrm{II}}(\mathrm{Aryl})\left(\mathrm{CF}_{3}\right)$ [71] to prepare $\mathrm{Ar}^{-\mathrm{CF}_{3}}$ and Romashov et al. [72] used 
[(Xantphos) $\left.\mathrm{Pd}\left(\mathrm{CF}_{3}\right)(\mathrm{Ph})\right]$ for preparation of $\mathrm{Ar}-\mathrm{CF}_{3}$. It is also noted that Buchwald et al. [73] prepared trifluoromethylated aromatic compounds using palladium complex as a catalyst $(\mathrm{Pd}(0)-\mathrm{Pd}(\mathrm{II}))$, where heating $\mathrm{Ar}-\mathrm{Cl}, \mathrm{TESCF}_{3}$ (triethylsilyl) and $\mathrm{KF}$ in dioxane at $120{ }^{\circ} \mathrm{C}$ gave an excellent yield (up to $80 \%$ ) (Scheme 15).

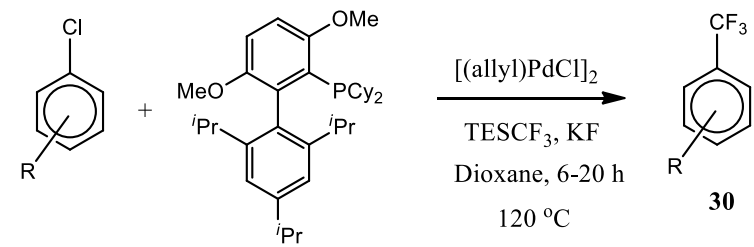

Scheme 15. Palladium-catalyzed trifluoromethylation of aromatic systems.

\subsubsection{Ni catalyzed reaction}

Sanford et al. prepared $\mathrm{Ni}^{\mathrm{II}}-\mathrm{CF}_{3}$ [74] and $\mathrm{Ni}^{\mathrm{IV}}-\mathrm{CF}_{3}$ [75] complexes to introduce the trifluoromethyl $\left(\mathrm{CF}_{3}\right)$ group on arene and heteroarenes. Nebra et al. [76] used $\left[(\mathrm{Py})_{2} \mathrm{Ni}^{\mathrm{IV}} \mathrm{F}_{2}-\left(\mathrm{CF}_{3}\right)_{2}\right]$ for the $\mathrm{C}-\mathrm{H}$ functionalization of aromatic compounds up to a $94 \%$ yield (Scheme 16).

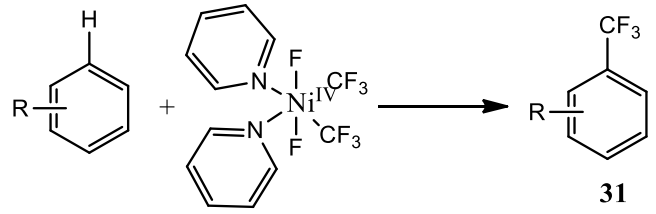

Scheme 16. Nickel catalyzed trifluoromethylation of aromatic systems.

\subsection{Electrochemical method}

\subsubsection{Electrosynthesis of arenes and heteroarenes}

Alternating current electrolysis (ACE) is a technique where an alternating voltage $( \pm v)$ is applied to push the redox transformations. In an electrochemical method, first, triflyl chloride generates trifluoromethyl $\left(\mathrm{CF}_{3}\right)$ radical (Scheme 17) under negative electrode potential and, next, this trifluoromethyl $\left(\mathrm{CF}_{3}\right)$ reacts with the aromatic system (2acetylpyrrole) and forms a radical intermediate. When the voltage is reversed, the intermediate is oxidized to allylic cation, and subsequent deprotonation results in the final product. Instead of paired electrolysis, the ACE method gives a better yield of up to 84\% [77]. This method successfully prepares trifluoromethylated pyrroles, arenes, furans, thiophenes, and imidazole with moderate to high yield. Since the intermediate involves the loss of aromaticity, electrosynthesis gave a low yield. 


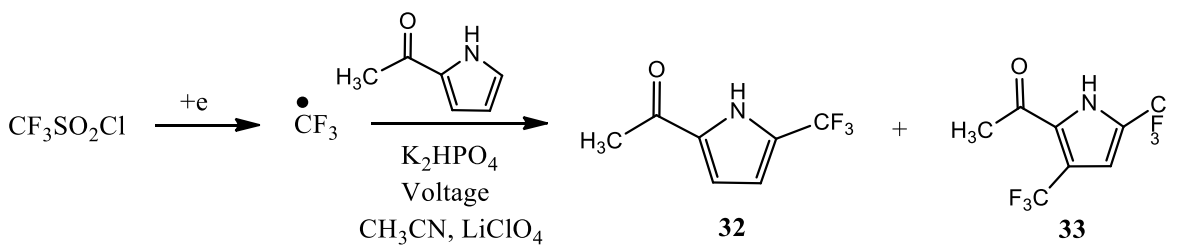

Scheme 17. Electrosynthesis of aromatic arenes.

Studer's research group [78] has also published an electrochemical method for the synthesis of trifluoromethylated phenanthridine by using Togni reagent with the highest yield up to $77 \%$.

\subsection{Light-driven}

In the light-driven method, it uses light and some photocatalyst, such as Iridium (III), $\left[\mathrm{Ru}(\mathrm{bpy})_{3}\right]^{2+}$. In addition, as a source of trifluoromethyl group Togni reagent [79], Umemoto reagent [80], Ruppert-Prakash [81], $\mathrm{CF}_{3} \mathrm{I}$ [82], $\mathrm{CF}_{3} \mathrm{SO}_{2} \mathrm{Cl}$ [83], $\mathrm{CF}_{3} \mathrm{SO}_{2} \mathrm{Na}$ [84], and $\left(\mathrm{CF}_{3} \mathrm{SO}_{2}\right)_{2} \mathrm{Zn}$ [85] are used. In this method different types of trifluoromethylated alkene [86-89], azides [90], aromatic compounds [91-92] (scheme 3.9.1), $\alpha, \beta$-unsaturated carboxylic acids [93], and benzimidazoles [94] were prepared. The advantage of the photochemical method is that it is not expensive [91] and toxic metal catalyst is not used in some special cases (Scheme 18) since most of the pharmaceutical industry needs substrates free of metals. In some cases, the removal of metal is very tough and induces extra cost of substrates.

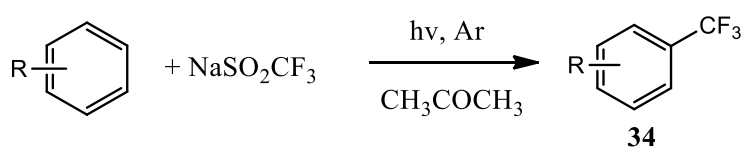

Scheme 18. Trifluoromethylation on aromatic compounds.

\subsection{Umemoto reagent}

\subsubsection{Types of Umemoto reagents}

Umemoto and coworkers [95,96] have developed some reagents (Scheme 19) that are used to incorporate trifluoromethyl $\left(\mathrm{CF}_{3}\right)$ on different types of aromatic systems as an electrophile. $S$-(trifluoromethyl)dibenzothiophenium triflate (35) is used in synthesis due to its better reactivity. This reagent (35) has a better yield during synthesis than others.<smiles>FC(F)(F)[s+]1c2ccccc2c2ccccc21</smiles>

35<smiles>FC(F)(F)[se+]1c2ccccc2c2ccccc21</smiles>

36<smiles>FC(F)(F)[Te+](c1ccccc1)c1ccccc1</smiles>

37

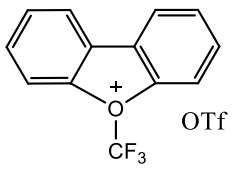

38

Scheme 19. Umemoto reagents. 
2-mercaptobiphenyl was placed in dry dimethylformamide (DMF) and cooled in an ice bath. It was added $\mathrm{NaH}$, and when hydrogen gas evolution is ceased, it was added $\mathrm{CF}_{3} \mathrm{Br}$ gas and irradiated by $\mathrm{Hg}$ lamp for $2 \mathrm{~h}$. Finally, an oily product was formed (82\%). Next, $\mathrm{F}_{2}$ and $\mathrm{N}_{2}$ were introduced (1:9 mixture) with the addition of $\mathrm{TfOH}$ in $\mathrm{CCl}_{3} \mathrm{~F}$ at $0{ }^{\circ} \mathrm{C}$. The reaction warmed to room temperature and after the addition of $\mathrm{Et}_{2} \mathrm{O}$, white precipitate of $S$ -(trifluoromethyl)dibenzothiophenium triflate (35) (Scheme 20 ) was formed (83\% yield).
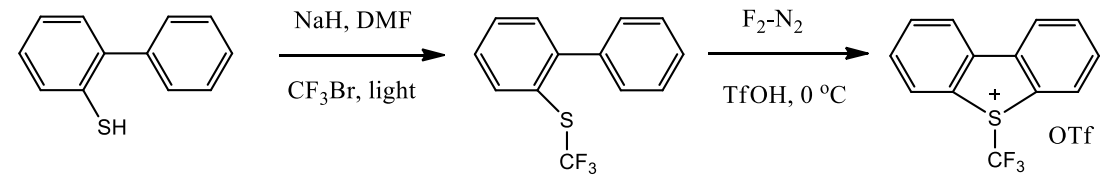

Scheme 20. Synthesis of $S$-(trifluoromethyl)dibenzothiophenium triflate.

39

Akita et al. [97] prepared different types of lactones by using Umemoto reagent. In this method, it was found that bases $\mathrm{K}_{2} \mathrm{HPO}_{4}$ or $\mathrm{K}_{2} \mathrm{CO}_{3}$ helped in reaction yield, and $\left[\mathrm{Ru}(\mathrm{bpy})_{3}\left(\mathrm{PF}_{6}\right)_{2}\right]$ was used as a photoredox catalyst. The yield was found in $28-85 \%$ (Scheme 21).
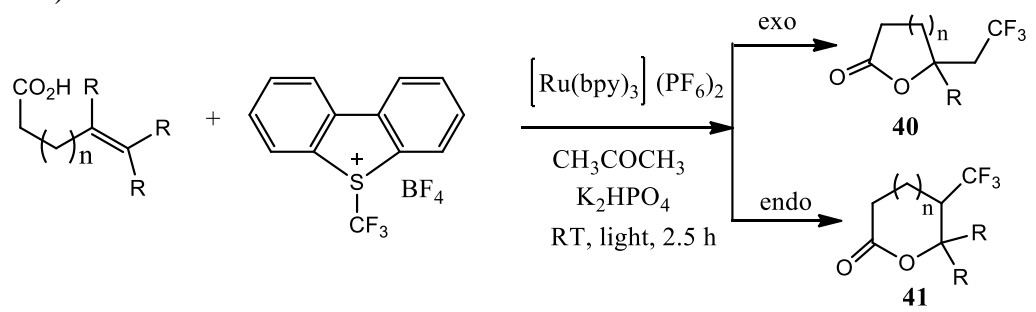

Scheme 21. Synthesis of trifluoromethylated lactone by using Umemoto reagent.

Xiao et al. [98] (Scheme 22) and She et al. [99] (Scheme 23) research groups prepared different types of pyrazolines, isoxazolines, and arylalkenes by using Umemoto reagents.<smiles>[R]NN=C([R])CC([R])=C</smiles>

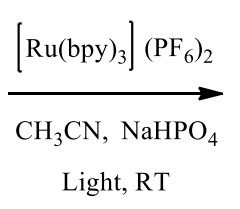<smiles>[R]C1=NN([R])C([R])(CC(F)(F)F)C1</smiles>

Scheme 22. Synthesis of $\beta, \gamma$-unsaturated hydrazones.
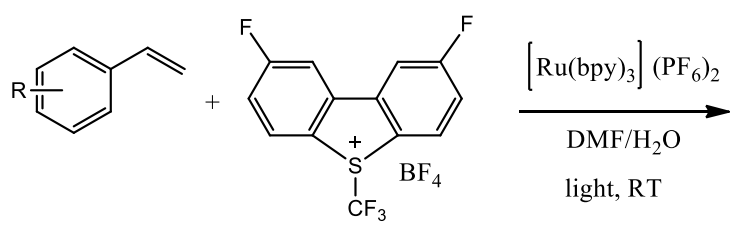<smiles>[R]C(=O)OC(CC(F)(F)F)c1ccccc1</smiles>

Scheme 23. Photocatalytic trifluromethylation of arylalkenes. 
Gouverneur et al. [100] focused on inactivated alkene with $\mathrm{Ru}(\mathrm{bpy})_{3} \mathrm{Cl}_{2}$ as photocatalyst in $\mathrm{MeOH}$ and light-driven product with a moderate yield of $64 \% . \mathrm{CF}_{3} \mathrm{H}$ is added to alkene where Umemoto reagent acts as trifluoromethyl $\mathrm{CF}_{3}$ donor and methanol as hydrogen donor with maintaining regioselectivity.

\subsection{Future direction}

Trifluoromethylating reagents still have some problems like air and moisture sensitivity. It is also noted that a few reagents are very expensive. Besides, one reagent is not effective for all types of substrates, like trifluromethylation of alkene, amine, amide, arene, heteroarene, etc. So, a common reagent that will be very cheap, stable, and effective for all types of substrates may open a new window for the development of trifluoromethylated substrates. Currently, non-metallic reagents are very important for developing new drugs. During the development of new materials, it may consider following solvents such as MeCN, DMF, DMSO. It is seen in literature that a few groups did the reaction in $\mathrm{MeOH}$ and used water as a solvent. Since toxic chemicals may generate during the reaction, a facile route is still necessary to develop in the future.

\section{Conclusion}

This review is illustrating clearly some important trifluoromethylated reagents and their effectiveness for different types of substrates. Although a lot of reviews exist, this review will be very effective for getting knowledge about the $\mathrm{CF}_{3}$ reagents, as here everything is mentioned very briefly to make it interesting to the reader. Additionally, it will be very helpful as a practical guide if anyone wants to develop some new materials either reagent or substrates. The synthetic methods of the reagents are discussed citing their original articles as reference.

\section{References}

1. J. Wang, M. S. Roselló, J. L. Aceña, C. D. Pozo, A. E. Sorochinsky, S. Fustero, V. A. Soloshonok, and H. Liu, Chem. Rev. 114, 2432 (2014). https://doi.org/10.1021/cr4002879

2. S. Purser, P. R. Moore, S. Swallow, and V. Gouverneur, Chem. Soc. Rev. 37, 320 (2008). https://doi.org/10.1039/B610213C

3. K. Müller, C. Faeh, and F. Diederich, Science 317, 1881 (2007). https://doi.org/10.1126/science.1131943

4. P. Pommier, A. Keita, S. W. Robert, B. Dellac, and H. C. Mundt, Rev. de Méd. Vétér. 1, 41 (2003).

5. P. Jeschke. Chem. Bio. Chem. 5, 570 (2004). https://doi.org/10.1002/cbic.200300833

6. P. Maienfisch and R. G. Hall, CHIMIA Int. J. Chem. 58, 93 (2004). https://doi.org/10.2533/000942904777678091

7. A. Aajoud, M. Raveton, D. A. Isghi, M. Tissut, and P. Ravanel. J. Agri. Food Chem. 56, 3732 (2008). https://doi.org/10.1021/jf800043h

8. E. P. Gillis, K. J. Eastman, M. D. Hill, D. J. Donnelly, and N. A. Meanwell, J. Med. Chem. 58, 8315 (2015). https://doi.org/10.1021/acs.jmedchem.5b00258

9. D. Katayev, J. Václavík, F. Brüning, B. Commare, and A. Togni, Chem. Commun. 52, 4049 (2016). https://doi.org/10.1039/C6CC00700G 
10. R. L. Lintvedt and H. F. Jr. Holtzclaw, J. Am. Chem. Soc. 88, 2713 (1966). https://doi.org/10.1021/ja00964a018

11. T. Furuya, A. S. Kamlet, and T. Ritter, Nature 473, 470 (2011). https://doi.org/10.1038/nature10108

12. O. A. Tomashenko and V. V. Grushin, Chem. Rev. 111, 4475 (2011). https://doi.org/10.1021/cr1004293

13. N. Shibata, A. Matsnev, and D. Cahard, Beilstein J. Org. Chem. 6, 1 (2010). https://doi.org/10.3762/bjoc.6.65

14. V. Matousek, E. Pietrasiak, R. Schwenk, and A. Togni, J. Org. Chem. 78, 6763 (2013). https://doi.org/10.1021/jo400774u

15. I. Ruppert, K. Schlich, and W. Volbach, Tetrahedron. lett. 25, 2195 (1984). https://doi.org/10.1016/S0040-4039(01)80208-2

16. P. Eisenberger, S. Gischig, and A. Togni, Chem. A Eur. J. 1, 2579 (2006). https://doi.org/10.1002/chem.200501052

17. H. Li, Synlett. 23, 2289 (2012). https://doi.org/10.1055/s-0032-1317176

18. B. R. Langlois, E. Laurent, and N. Roidot, Tetrahedron lett. 32, 7525 (1991). https://doi.org/10.1016/0040-4039(91)80524-A

19. T. Umemoto, Chem. Rev. 96, 1757 (1996). https://doi.org/10.1021/cr941149u

20. G. K. S. Prakash and A. K. Yudin, Chem. Rev. 97, 757 (1997). https://doi.org/10.1021/cr9408991

21. C. Zhang, Org. Biomol. Chem. 12, 6580 (2014). https://doi.org/10.1039/C4OB00671B

22. J. A. Ma and D. Cahard, J. Fluorine Chem. 128, 975 (2007). https://doi.org/10.1016/j.jfluchem.2007.04.026

23. W. R. Dolbier, Chem. Rev. 96, 1557 (1996). https://doi.org/10.1021/cr941142c

24. R. Littich and P. J. H. Scott, Angew. Chem. Int. Ed. 51, 1106 (2012). https://doi.org/10.1002/anie.201106785

25. M. Salwiczek, E. K. Nyakatura, U. I. M. Gerling, S. Ye, and B. Koksch, Chem. Soc. Rev. 41, 2135 (2012). https://doi.org/10.1039/C1CS15241F

26. M. Bremer, P. Kirsch, M. K. Memmer, and K. Tarumi, Angew. Chem . Int. Ed. 52, 8880(2013). https://doi.org/10.1002/anie.201300903

27. W. Lu, J. Kuwabara, T. Iijima, H. Higashimura, H. Hayashi, and T. Kanbara, Macromolecules 45, 4128 (2012). https://doi.org/10.1021/ma3004899

28. D. Sagdullina, N. Lukashkin, A. Parfenov, K. Lyssenko, and P. Troshin, Synth. Metals 260, ID 116289 (2020). https://doi.org/10.1016/j.synthmet.2019.116289

29. L. Zhang, J. Niu, Y. Li, Y. Wang, and D. Sun, Environ. Pollut. 180, 34 (2013). https://doi.org/10.1016/j.envpol.2013.04.031

30. R. Landau and R. Rosen, Ind. Eng. Chem. 39, 281 (1947). https://doi.org/10.1021/ie50447a609

31. H. X. Song, Q. Y. Han, C. L. Zhao, and C. P. Zhang, Green Chem. 20, 1662 (2018). https://doi.org/10.1039/C8GC00078F

32. J. Charpentier, N. Fruh, and A. Togni, Chem. Rev. 115, 650 (2015). https://doi.org/10.1021/cr500223h

33. X. H. Xu, K. Matsuzaki, and N. Shibata, Chem. Rev. 115, 731 (2015). https://doi.org/10.1021/cr500193b

34. X. Pan, H. Xia, and J. Wu, Org. Chem. Front. 3, 1163 (2016). https://doi.org/10.1039/C6QO00153J

35. C. Ni and J. Hu, Chem. Soc. Rev. 45, 5441 (2016). https://doi.org/10.1039/C6CS00351F

36. J. Hu, W. Zhang, and F. Wang, Chem. Commun. 48, 7465 (2009).

37. J. P. Brand, D. F. González, S. Nicolai, and J. Waser, Chem. Commun. 47, 102 (2011). https://doi.org/10.1039/C0CC02265A

38. E. Merino and C. Nevado, Chem. Soc. Rev. 43, 6598 (2014). https://doi.org/10.1039/C4CS00025K

39. C. Yang, A. Hassanpour, K. Ghorbanpour, S. Addolmohammadi, and E. Vessally, RSC Adv. 9, ID 27625 (2019). https://doi.org/10.1039/C9RA04170B 
40. C. Lai and T. E. Mallouk, J. Chem. Soc., Chem. Commun. 17, 1359 (1993). https://doi.org/10.1039/c39930001359

41. Q. Wang, B. Wang, H. Deng, Y. Shangguan, Y. Lin, Y. Zhang, Z. Zhang, Y. Xiao, H. Guo, and C. Zhang, J. Org. Chem. 84, 1006 (2019). https://doi.org/10.1021/acs.joc.8b02997

42. S. L. Zhang and C. Xiao, J. Org. Chem. 83, 10908 (2018). https://doi.org/10.1021/acs.joc.8b01586

43. S. L. Zhang, C. Xiao, and H. X. Wan, Dalton Trans. 47, 4779 (2018). https://doi.org/10.1039/C8DT00291F

44. J. M. Larsson, S. R. Pathipati, and K. J. Szabó, J. Org. Chem. 78, 7330 (2013). https://doi.org/10.1021/jo4010074

45. S. L. Zhang and W. F. Bie, RSC adv. 6, 70902 (2016). https://doi.org/10.1039/C6RA10302B

46. A. Lishchynskyi, G. Berthon, and V. V. Grushin, Chem. Commun. 50, 10237 (2014). https://doi.org/10.1039/C4CC04930F

47. H. Shen, Z. Liu, P. Zhang, X. Tan, Z. Zhang, and C. Li, J. Am. Chem. Soc. 139, 9843 (2017). https://doi.org/10.1021/jacs.7b06044

48. X. Tan, Z. Liu, H. Shen, P. Zhang, Z. Zhang, and C. Li, J. Am. Chem. Soc. 139, 12430 (2017). https://doi.org/10.1021/jacs.7b07944

49. M. G. Mormino, P. S. Fier, and J. F. Hartwig, Org. Lett. 16, 1744 (2014). https://doi.org/10.1021/ol500422t

50. H. Morimoto, T. Tsubogo, N. D. Litvinas, and J. F. Hartwig, Angew Chem. Int. Ed. 50, 3793 (2011). https://doi.org/10.1002/anie.201100633

51. G. G. Dubinina, H. Furutachi, and D. A. Vicic, J. Am. Chem. Soc. 130, 8600 (2008). https://doi.org/10.1021/ja802946s

52. M. Chen and S. L. Buchwald, Angew. Chem. Int. Ed. 125, 11842 (2013). https://doi.org/10.1002/ange.201306094

53. P. Eisenberger, I. Kieltsch, N. Armanino, and A. Togni, Chem. Commun. 13, 1575 (2008). https://doi.org/10.1039/b801424h

54. R. Beniazza, M. Douarre, D. Lastécouères, and J. M. Vincent, Chem. Commun. 53, 3547 (2017). https://doi.org/10.1039/C7CC00214A

55. T. Liu and Q. Shen, Org. Lett. 13, 2342 (2011). https://doi.org/10.1021/ol2005903

56. J. Wang, K. Sun, X. Chen, T. Chen, Y. Liu, L. Qu, Y. Zhao, and B. Yu, Org. Lett. 21, 1863 (2019). https://doi.org/10.1021/acs.orglett.9b00465

57. X. Q. Mou, F. M. Rong, H. Zhang, G. Chen, and G. He, Org. Lett. 21, 4657 (2019). https://doi.org/10.1021/acs.orglett.9b01552

58. Y. Chen, G. Ma, and H. Gong, Org. Lett. 20, 4677 (2018). https://doi.org/10.1021/acs.orglett.8b02005

59. W. C. Smith, C. W. Tullock, E. L. Muetterties, W. R. Hasek, F. S. Fawcett, V. A. Engelhardt, and D. D. Coffman, J. Am. Chem. Soc. 81, 3165 (1959). https://doi.org/10.1021/ja01521a086

60. W. R. Hasek, W. C. Smith, and V. A. Engelhardt, J. Am. Chem. Soc. 82, 543 (1960). https://doi.org/10.1021/ja01488a012

61. S. Trofymchuk, M. Y. Bugera, A. A. Klipkov, B. Razhyk, S. Semenov, K. Tarasenko, V. S. Starova, O. A. Zaporozhets, O. Y. Tananaiko, A. N. Alekseenko, Y. Pustovit, O. Kiriakov, I. I. Gerus, A. A. Tolmachev, and P. K. Mykhailiuk, J. Org. Chem. 85, 3110 (2020). https://doi.org/10.1021/acs.joc.9b03011

62. M. Bugera, S. Trofymchuk, K. Tarasenko, O. Zaporozhets, Y. Pustovit, and P. K. Mykhailiuk, J. Org. Chem. 84, 16105 (2019). https://doi.org/10.1021/acs.joc.9b02596

63. J. A. Kautzky, T. Wang, R. W. Evans, and D. W. C. MacMillan, J. Am. Chem. Soc. 140, 6522 (2018). https://doi.org/10.1021/jacs.8b02650

64. V. Krishnamurti, S. B. Munoz, X. Ispizua-Rodriguez, J. Vickerman, T. Mathew, and G. K. S. Prakash, Chem. Commun. 54, 10574 (2018). https://doi.org/10.1039/C8CC04907F

65. D. L. Browne, Angew. Chem. Int. Ed. 53, 1482 (2014). https://doi.org/10.1002/anie.201308997

66. W. Wei, J. Wen, D. Yang, X. Liu, M. Guo, R. Dong, and H. Wang, J. Org. Chem. 79, 4225 (2014). https://doi.org/10.1021/jo500515x 
67. F. Yang, P. Klumphu, Y. M. Liang, and B. H. Lipshutz, Chem. Commun. 50, 936 (2014). https://doi.org/10.1039/C3CC48131J

68. Y. Ye, S. A. Künzi, and M. S. Sanford, Org. Lett. 14, 4979 (2012). https://doi.org/10.1021/ol3022726

69. W. G. Shen, Q. Y. Wu, X. Y. Gong, G. Z. Ao, and F. Liu, Green Chem. 21, 2983 (2019). https://doi.org/10.1039/C9GC00886A

70. N. D. Ball, J. W. Kampf, and M. S. Sanford, J. Am. Chem. Soc. 132, 2878 (2010). https://doi.org/10.1021/ja100955x

71. N. D. Ball, J. B. Gary, Y. Ye, and M. S. Sanford, J. Am. Chem. Soc. 133, 7577 (2011). https://doi.org/10.1021/ja201726q

72. V. I. Bakhmutov, F. Bozoglian, K. Gomez, G. Gonzalez, V. V. Grushin, S. A. Macgregor, E. Martin, F. M. Miloserdov, M. A. Novikov, J. A. Panetier, and L. V. Romashov, Organomet. 31, 1315 (2012). https://doi.org/10.1021/om200985g

73. E. J. Cho, T. D. Senecal, T. Kinzel, Y. Zhang, D. A. Watson, and S. L. Buchwald, Science 128, 1679 (2010).

74. J. R. Bour, N. M. Camasso, and M. S. Sanford, J. Am. Chem. Soc. 137, 8034 (2015). https://doi.org/10.1021/jacs.5b04892

75. E. A. Meucci, S. N. Nguyen, N. M. Camasso, E. Chong, A. Ariafard, A. J. Canty, and M. S. Sanford, J. Am. Chem. Soc. 141, 12872 (2019). https://doi.org/10.1021/jacs.9b06383

76. F. D'Accriscio, P. Borja, N. S. Merceron, M. F. Boutignon, N. Mézailles, and N. Nebra, Angew. Chem. Int. Ed. 56, 12898 (2017). https://doi.org/10.1002/anie.201706237

77. S. Rodrigo, C. Um, J. C. Mixdorf, D. Gunasekera, H. M. Nguyen, and L. Luo, Org. Lett. 22, 6719 (2020). https://doi.org/10.1021/acs.orglett.0c01906

78. M. Lübbesmeyer, D. Leifert, H. Schäfer, and A. Studer, Chem. Commun. 54, 2240 (2018). https://doi.org/10.1039/C7CC09302K

79. R. Tomita, Y. Yasu, T. Koike, and M. Akita, Angew. Chem. Int. Ed. 53, 7092 (2014). https://doi.org/10.1002/anie.201482871

80. J. J. Dai, C. Fang, B. Xiao, J. Yi, J. Xu, Z. J. Liu, X. Lu, L. Liu, and Y. Fu, J. Am. Chem. Soc. 135, 8436 (2013). https://doi.org/10.1021/ja404217t

81. Y. F. Wang, G. H. Lonca, and S. Chiba, Angew. Chem. Int. Ed. 53, 1067 (2014). https://doi.org/10.1002/anie.201307846g

82. N. Iqbal, J. Jung, S. Park, and E. J. Cho, Angew. Chem. Int. Ed. 53, 539 (2014). https://doi.org/10.1002/anie.201308735

83. D. A. Nagib and D. W. C. MacMillan, Nature 480, 224 (2011). https://doi.org/10.1038/nature10647

84. Y. Yang, Y. Liu, Y. Jiang, Y. Zhang, and D. A. Vicic, J. Org. Chem. 80, 6639 (2015). https://doi.org/10.1021/acs.joc.5b00781

85. Y. Fujiwara, J. A. Dixon, F. O'Hara, E. D. Funder, D. D. Dixon, R. A. Rodriguez, R. D. Baxter, B. Herle, N. Sach, M. R. Collins, Y. Ishihara, and P. S. Baran, Nature 492, 95 (2012). https://doi.org/10.1038/nature11680

86. Y. Yasu, T. Koike, and M. Akita, Chem. Commun. 49, 2037 (2013). https://doi.org/10.1039/c3cc39235j

87. X. L. Yu, J. R. Chen, D. Z. Chen, and W. J. Xiao, Chem. Commun. 52, 8275 (2016). https://doi.org/10.1039/C6CC03335K

88. Y. T. He, D. Kang, I. Kim, and S. Hong, Green Chem. 20, 5209 (2018). https://doi.org/10.1039/C8GC02782J

89. T. Koike and M. Akita, Acc. Chem. Res. 49, 1937 (2016). https://doi.org/10.1021/acs.accounts.6b00268

90. H. T. Qin, S. W. Wu, J. L. Liu, and F. Liu, Chem. Commun. 53, 1696 (2017). https://doi.org/10.1039/C6CC10035J

91. L. Li, X. Mu, W. Liu, Y. Wang, Z. Mi, and C. J. Li, J. Am. Chem. Soc. 138, 5809 (2016). https://doi.org/10.1021/jacs.6b02782 
92. Y. Ji, T. Brueckl, R. D. Baxter, Y. Fujiwara, I. B. Seiple, S. Su, D. G. Blackmond, and P. S. Baran, Proc. Natl. Acad. Sci. 108, 14411 (2011). https://doi.org/10.1073/pnas.1109059108

93. P. Xu, A. Abdukader, K. Hu, Y. Cheng, and C. Zhu, Chem. Commun. 50, 2308 (2014). https://doi.org/10.1039/C3CC48598F

94. G. L. Gao, C. Yang, and W. Xia, Chem. Commun. 53, 1041 (2017). https://doi.org/10.1039/C6CC08975E

95. T. Umemoto and S. Ishihara, J. Am. Chem. Soc. 115, 2156 (1993). https://doi.org/10.1021/ja00059a009

96. T. Umemoto, K. Adachi, and S. Ishihara, J. Org. Chem. 72, 6905 (2007). https://doi.org/10.1021/jo070896r

97. Y. Yasu, Y. Arai, R. Tomita, T. Koike, and M. Akita, Org. Lett. 16, 780 (2014). https://doi.org/10.1021/o1403500y

98. Q. Wei, J. R. Chen, X. Q. Hu, X. C. Yang, B. Lu, and W. J. Xiao, Org. Lett. 17, 4464 (2015). https://doi.org/10.1021/acs.orglett.5b02118

99. X. Zhou, G. Li, Z. Shao, K. Fang, H. Gao, Y. Li, and Y. She, Org. Biomol. Chem. 17, 24 (2019). https://doi.org/10.1039/C8OB02239A

100. S. Mizuta, S. Verhoog, K. M. Engle, T. Khotavivattana, M. O'duill, K. Wheelhouse, G. Rassias, M. Médebielle, and V. Gouverneur, J. Am. Chem. Soc. 135, 2505 (2013). https://doi.org/10.1021/ja401022x 